\title{
MITTEILUNG
}

\section{International Institute of Refrigeration Forthcoming Meeting}

Food Science, Refrigeration, and Air Conditioning Joint Meeting of Commissions C2, D1, D2, D3 \& E1

Melbourne, Australia, 6th - 10th September, 1976

The Australian National Committee for the I.I.R. is organizing a Joint Meeting of Commissions in Melbourne in September, 1976. This will be the first occasion on which the Institute has held a meeting in that country, and it is being arranged by the Committee in collaboration with local professional and technological Societies.

The aim of the meeting is to bring Australian research and development in the relevant fields to the notice of an international audience, and to acquaint Australien science and industry with current work being carried out in other countries.

A Call for Papers for the meeting will be issued shortly, setting out the selected theme and a list of preferred topics. Papers will however also be invited in the general areas of interest of the five Commissions. Limited funds will be available to assist selected authors with travel costs.

The organizer of the meeting is Mr. F. G. Hogg, I.I.R. Liaison Offizer in Australia, from whom further details can be obtained. His address is P.O. Box 26, Fighett, Victoria, 3190, Australia. 